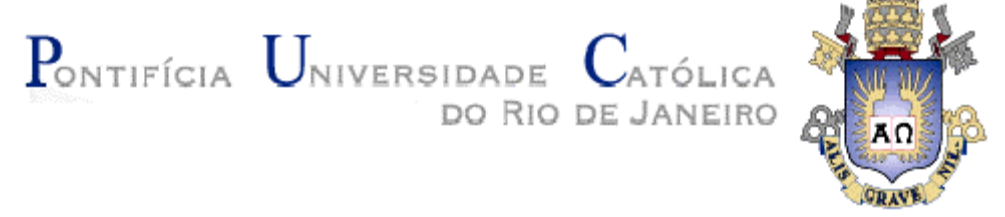

LIVIA KLEIN MARQUES DA CUNHA

\title{
CONCEPÇÕES E PRÁTICAS MIDIÁTICAS DE PROFESSORES DE SALA DE LEITURA PÓLO DO RIO DE JENEIRO
}

\author{
Dissertação de Mestrado \\ Dissertação apresentada como requisitos \\ parcial para obtenção do grau de Mestre pelo \\ Programa de Pós-Graduação em Educação do \\ Departamento de Educação da PUC-Rio. \\ Orientador: Profa ${ }^{a}$ Rosalia Maria Duarte
}

Rio de Janeiro

Abril de 2006 


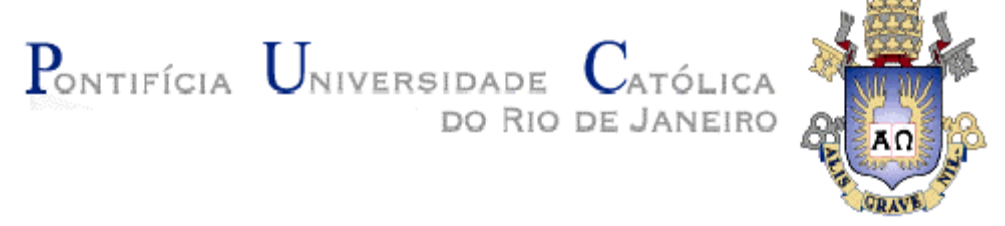

Livia Klein Marques da Cunha

Concepções e Práticas Midiáticas de Professores de Sala de Leitura Pólo do Rio de Janeiro

Dissertação apresentada como requisito parcial para obtenção do grau de Mestre pelo Programa de Pós-Graduação em Educação do Departamento de Educação do Centro de Teologia e Ciências Humanas da PUC-Rio. Aprovada pela Comissão Examinadora abaixo assinada.

\author{
Profa. Rosália Maria Duarte \\ Orientadora \\ Departamento de Educação - PUC-Rio
}

Prof ${ }^{a}$ Maria Apparecida C. Mamede Neves

Departamento de Educação - PUC-Rio

Profa. Mônica Rabello de Castro

UNESA

Prof. Paulo Fernando C. de Andrade Coordenador Setorial do Centro de Teologia e Ciências Humanas

Rio de Janeiro, 12 de abril de 2006. 
Todos os direitos reservados. É proibida a reprodução total ou parcial do trabalho sem autorização da universidade, da autora e do orientador.

\section{Livia Klein Marques da Cunha}

Lívia Klein Marques da Cunha graduou-se em Pedagogia licenciatura plena em Educação Especial e Magistério das Matérias Pedagógicas pela UERJ em 1999 e licenciatura plena em Educação Infantil em 2002, pela mesma universidade. Trabalhou desde sua formação ate 2004 com pessoas portadoras de necessidades especiais, exercendo as funções de professora e coordenadora de atividades pedagógicas em diferentes instituições. Em 2001 tornou-se Psicopedagoga pela UFRJ apresentando a monografia "Afetividade, interações sociais em sala de aula e psicopedagogia”. Em 2006 concluiu o Curso de Mestrado em Educação na Puc-Rio apresentando a dissertação "Concepções e práticas midiaticas de professores de sala de leitura pólo do Rio de Janeiro". Desde 2005 trabalha como professora do ensino fundamental na Associação Britânica de Educação.

Ficha Catalográfica

$$
\begin{aligned}
& \text { Cunha, Livia Klein Marques da } \\
& \text { Concepções e práticas midiáticas de } \\
& \text { professores de sala de leitura pólo do Rio de } \\
& \text { Janeiro / Livia Klein Marques da Cunha ; } \\
& \text { orientadora: Rosalia Maria Duarte. - Rio de Janeiro } \\
& \text { : PUC, Departamento de Educação, 2006. } \\
& 110 \text { f. : il. (col.) ; } 30 \mathrm{~cm} \\
& \text { Dissertação (mestrado) - Pontifícia } \\
& \text { Universidade Católica do Rio de Janeiro, } \\
& \text { Departamento de Educação }
\end{aligned}
$$

1. Educação - Teses. 2. Mídia. 3. Sala de leitura. 4. Professores. 5. Formação. I. Duarte, Rosalia Maria. II. Pontifícia Universidade Católica do Rio de Janeiro. Departamento de Educação. III. Título. 
A minha mãe querida, Geisa, por todo carinho, paciência e amorque me dedica e ao meu pai, Sergio, pela sua constante preocupação .

Ao Mark, que me ajudou a começar essa trajetória e me deu forças para continuá-la nos momentos mais dificeis, mesmo distante.

Às minhas queridas amigas, Vivi, Aline e Bella, pacientes e incentivadoras sempre!!!!

Ao Felipe, que faz o meu sorriso muito mais feliz! 


\section{Agradecimentos}

Gostaria de agradecer aos professores de sala de leitura pólo do município do Rio de Janeiro, que me concederam entrevistas e proporcionaram a realização deste trabalho e, em especial, aos professores da sala de leitura e à diretora da escola Tristão de Athayde, sempre muito solícitos, atenciosos e prontos a esclarecer minhas dúvidas e a contribuir com sua experiência.

À Simone, diretora da Divisão de Mídia Educação da Secretaria Municipal de Educação do Rio de Janeiro, pelas entrevistas e apoio recebido.

Aos professores do Mestrado que contribuíram com minha formação e aos companheiros que caminharam comigo nestes dois anos, possibilitando momentos de troca e reflexão.

Aos meus familiares e amigos.

À minha querida orientadora, Rosália Duarte, pela paciência, inteligência, sabedoria e amizade com a qual conduziu essa tarefa de guiar meus passos na realização deste trabalho. 


\section{Resumo}

Cunha, Livia Klein Marques da; Duarte, Rosalia Maria. Concepções e Práticas Midiáticas de Professores de Sala de Leitura Pólo do Rio de Janeiro. Rio de Janeiro, 2006, 144p. Dissertação de Mestrado Departamento de Educação, Pontifícia Universidade Católica do Rio de Janeiro.

Este estudo procura mapear e analisar concepções e práticas mídiaeducativas de professores de Sala de Leitura Pólo da rede municipal do Rio de Janeiro. Tendo optado por uma metodologia de base qualitativa, foram realizadas entrevistas com professores de Sala de Leitura, análises de documentos oficiais da SME e observações de campo. Para contextualizar as Salas de Leitura, foram analisados documentos oficiais que regulamentaram sua implementação e orientam sua organização e funcionamento. Verificou-se que, de espaços privilegiados de práticas leitoras de textos literários, estas salas foram sendo transformadas em espaços multimidiáticos, onde o uso das tecnologias da informação e da comunicação passou a ter grande importância. Através de entrevistas com professores de Sala de Leitura Pólo e de observações de suas práticas, procurou-se compreender melhor como estes profissionais entendem o uso dos diferentes tipos de mídias relacionado com a educação, tendo como referência a concepção de mídia-educação defendida por David Buckingham. Buscou-se, também, analisar como tem sido feita a formação dos professores para este tipo de trabalho.

Foi possível perceber que, apesar do discurso de boa parte dos entrevistados ter incorporado conceitos e teorias formulados por teóricos do campo, ainda há um longo caminho a percorrer para que a escola como um todo incorpore a mídia-educação enquanto processo de ampliação da capacidade de crítica e da criatividade dos estudantes e desenvolva práticas afinadas com estes objetivos, num contexto de mudanças significativas na formação dos professores.

\section{Palavras-chave:}

Mídia-educação, Sala de Leitura, Professores, Formação. 


\section{Abstract}

Cunha, Livia Klein Marques da; Duarte, Rosalia Maria (Advisor). "Media Concepts and Practices used by Reading Centre Room Teachers of Rio de Janeiro". Rio de Janeiro, 2006, 144 p. MSc. Dissertation - Departamento de Educação, Pontifícia Universidade Católica do Rio de Janeiro.

This study aims to map and analyze concepts and practices in mediaeducation used by teachers of the Reading Centre Rooms of the Rio de Janeiro municipal network. Using a qualitative basis of research, this study was made by some interviews with the reading room teachers, official document analyses, and practical observations. In order to contextualize the Reading Rooms, official documents that regularize their implementation and that guide their organization and functionality were analyzed. It was verified that, from privileged spaces for the reading practices of literary texts, these rooms had been transformed in multimedia spaces, where the use of information and communication technology had achieved great importance. Through interviewing teachers of some Reading Centre Rooms and observing their practices, this study tried to understand better how these professionals understand the use of different types of media related to the educational process, using the media-education proposal defended by David Buckingham as an important statement. Besides this, it had sought to analyze how they have been trained for this type of work.

It can be perceived that, although the replies of a large number of those interviewed already have some concepts and elements which are being discussed by researchers of this subject field, there is still a long way for schools to go on incorporating media-education as a process capable to improve the students criticism and creativity and to develop practices related to these objectives, in a significant context of changes in the teachers training..

\section{Key-words:}

Media-education, Reading room, Teachers, Training. 


\section{Sumário}

1. Introdução

2. Educação e Comunicação - áreas que se cruzam

2.1 Mídia-Educação como prática educativa e campo de pesquisa

3. Novas tecnologias e novos espaços: configurações das Salas de Leitura no Município do Rio de Janeiro

4. Os sujeitos da pesquisa e o trabalho de campo

4.1 O trabalho de campo: situações de contato

5. Análise do material empírico coletado

5.1 Mídia é comunicação, não é? É processo e é também meio concepções de mídia dos docentes

5.2 Aspectos relacionados à formação docente para o trabalho com mídias na escola

5.3 Práticas mídia-educativas: observações feitas na escola 73

5.4 Impasses e sugestões dos docentes para melhorar suas práticas

6. Considerações Finais

7. Referências Bibliográficas

8. Anexos 


\section{Figuras}

$\begin{array}{ll}\text { Figura } 1 & 74\end{array}$

$\begin{array}{ll}\text { Figura } 2 & 75\end{array}$

$\begin{array}{ll}\text { Figura } 3 & 76\end{array}$

$\begin{array}{ll}\text { Figura } 4 & 76\end{array}$

$\begin{array}{ll}\text { Figura } 5 & 77\end{array}$

$\begin{array}{lr}\text { Figura } 6 & 80\end{array}$

$\begin{array}{lr}\text { Figura } 7 & 81\end{array}$

$\begin{array}{lr}\text { Figura } 8 & 81\end{array}$

$\begin{array}{lr}\text { Figura } 9 & 82\end{array}$

$\begin{array}{ll}\text { Figura } 10 & 82\end{array}$

Figura 11

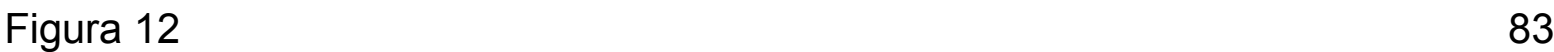

Figura $13 \quad 84$ 